\title{
The Characterization of chIFITMs in Avian Coronavirus Infection In Vivo, Ex Vivo and In Vitro
}

\author{
Angela Steyn ${ }^{1, *}$, Sarah Keep ${ }^{1}$, Erica Bickerton ${ }^{1}$ (D) and Mark Fife 1,2 $^{\text {, }}$ \\ 1 The Pirbright Institute, Pirbright, Woking GU24 0NF, UK; sarah.keep@pirbright.ac.uk (S.K.); \\ erica.bickerton@pirbright.ac.uk (E.B); mfife@aviagen.com (M.F.) \\ 2 AVIAGEN UK, Ltd. Newbridge, Midlothian EH28 8SZ, Scotland, UK \\ * Correspondence: angela.steyn@pirbright.ac.uk; Tel.: +44-(0)148-323-4762
}

Received: 20 July 2020; Accepted: 7 August 2020; Published: 10 August 2020

\begin{abstract}
The coronaviruses are a large family of enveloped RNA viruses that commonly cause gastrointestinal or respiratory illnesses in the infected host. Avian coronavirus infectious bronchitis virus (IBV) is a highly contagious respiratory pathogen of chickens that can affect the kidneys and reproductive systems resulting in bird mortality and decreased reproductivity. The interferon-inducible transmembrane (IFITM) proteins are activated in response to viral infections and represent a class of cellular restriction factors that restrict the replication of many viral pathogens. Here, we characterize the relative mRNA expression of the chicken IFITM genes in response to IBV infection, in vivo, ex vivo and in vitro using the pathogenic M41-CK strain, the nephropathogenic QX strain and the nonpathogenic Beaudette strain. In vivo we demonstrate a significant upregulation of chIFITM1, 2, 3 and 5 in M41-CK- and QX-infected trachea two days post-infection. In vitro infection with Beaudette, M41-CK and QX results in a significant upregulation of chIFITM1, 2 and 3 at $24 \mathrm{~h}$ post-infection. We confirmed a differential innate response following infection with distinct IBV strains and believe that our data provide new insights into the possible role of chIFITMs in early IBV infection.
\end{abstract}

Keywords: coronavirus; avian infectious bronchitis virus (IBV); interferon-inducible transmembrane (IFITM) proteins

\section{Introduction}

Coronaviruses encompass a large family of positive-stranded RNA viruses that cause a range of diseases in humans and animals [1]. The Coronaviridae family consists of two subfamilies, the Letovirinae and Orthocoronavirinae, the latter of which is divided into four genera named, $\alpha$-, $\beta-$, Delta- and Gammacoronavirus. The avian coronavirus, infectious bronchitis virus (IBV) is the prototype Gammacoronavirus. Notable members of the Betacoronavirus genus include the human coronaviruses, murine hepatitis virus (MHV), Middle Eastern respiratory syndrome coronavirus (MERS-CoV) [1-4], severe acute respiratory syndrome coronavirus (SARS-CoV) [2] and the virus responsible for COVID-19, SARS-CoV-2 [3].

Infectious bronchitis virus infects domestic fowl (Gallus gallus) and is the causative agent of a highly contagious respiratory disease, Infectious Bronchitis (IB). IBV replicates primarily in the tracheal epithelial cells of the respiratory tract, resulting in a decrease in tracheal ciliary activity and common-cold-like symptoms including snicking, tracheal rales and nasal discharge [5]. Secondary replication of IBV can occur in many non-respiratory tissues including the kidney, testes, oviduct and gastrointestinal tract [6,7]. The clinical symptoms presented by infected birds are dependent on several factors including the strain of IBV, of which there are many genetic variants and serotypes. The majority of IBV strains, including the Massachusetts (Mass) serotype M41 produce prominent 
respiratory disease [8]. In contrast, QX, an IBV strain first isolated in China from chickens with proventriculitis [9], is considered nephropathogenic and in addition to tracheal lesions, infection also induces prominent kidney lesions. QX infection results in a higher mortality rate [8] than a classical respiratory infection. The common features of all IBV infections include lethargy, weight loss and reduced egg production and quality [6]. IBV infection is therefore of major economic importance to the poultry industry worldwide and despite intensive control measures, remains prevalent [10].

The IBV genome contains a positive-sense single-stranded RNA molecule of approximately $27.6 \mathrm{~kb}$ in length $[11,12]$ which is polyadenylated at the $3^{\prime}$ end and contains a methylated cap at the $5^{\prime}$ end. The genome encodes 15 nonstructural proteins (nsp) that are expressed as part of two large polyproteins, pp1a and pplab, the latter is generated via a ribosomal frameshift $[13,14]$. The genome also encodes four major structural proteins; the nucleocapsid (N) protein, the membrane glycoprotein $(\mathrm{M})$, a small envelope protein (E) and the spike glycoprotein (S), as well as four confirmed accessory proteins, 3a, 3b, 5a and 5b [15]. These proteins play different roles in the replication cycle with $S$ notably mediating virus attachment and entry [16], thus being largely responsible for cell and host tropism [17-19]. The binding of a virus to the host cell is the first step in determining tissue and host specificity and ultimately pathogenicity $[19,20]$. Some viruses bind to abundant and universal host factors, resulting in the infection of various host species while other viruses, such as the coronaviruses, have a limited range of susceptible hosts $[19,21]$. Infectious bronchitis virus has a narrow host tropism and although this host tropism is restricted to chickens, the cell and tissue tropism in chickens differ substantially between different IBV strains [19,22].

Current IBV isolates present highly diverse antigenicity and emergent strains, that differ in antigenic properties, tissue tropism and pathogenicity, and are continuously being reported across the world [23,24]. IBV is currently controlled by the use of both live-attenuated and inactivated boost vaccine strains of varying serotypes such as Massachusetts, Connecticut and Arkansas. Chickens receive combinations of vaccine viruses in an effort to induce protective responses against multiple field strains; however, the cross-protection induced is limited and often short-lived [25-28]. In addition, the constant emergence of new variant IBV strains leads to outbreaks of the virus in vaccinated flocks resulting in significant economic losses to the poultry industry $[7,29,30]$. Therefore, the use of innate immune mediators to boost the innate immune system may be an alternative approach to control IBV infection [31].

In response to viral infection, nearly all vertebrate cells activate the innate immune response as a first line of defense [32,33]. The group of cytokines produced, type I interferons (IFNs), function to induce the expression of a cascade of interferon-stimulated genes (ISGs) resulting in an antiviral state [34]. These ISGs encode antiviral proteins that inhibit several stages of the viral lifecycle including viral entry, translation, replication, assembly and egress $[35,36]$. The interferon-inducible transmembrane proteins (IFITMs) are widely expressed IFN-inducible proteins that restrict the entry and therefore infection, by multiple pathogenic viruses including, influenza A virus (IAV), West Nile virus (WNV), dengue virus (DENV), severe acute respiratory syndrome coronavirus (SARS-CoV), vesicular stomatitis virus (VSV) and hepatitis C virus (HCV), among others [34,35,37-44]. Many studies have aimed to understand the mechanisms behind the antiviral activity of the IFITM proteins [39,45-48]. Early work showed that IFITMs are located on the endosomal membranes and block viral particles that have the receptors of restricted viruses [40]. Later work suggested that IFITMs restrict viral entry by changing the properties of cellular membranes [49] resulting in IFITM-sensitive viruses being blocked at the cell surface and becoming trapped in the endosomal pathway, ultimately preventing viral fusion $[40,45]$.

The IFITM protein family is encoded by five genes in humans, including the immune-related IFITM1, IFITM2 and IFITM3, as well as IFITM5 and IFITM10, which have no characterized roles in immunity [36]. IFITMs are present in a wide range of species: from amphibians, fish and birds to mammals. The chicken IFITM (chIFITM) genes are clustered on chromosome 5, and to date, four genes have been annotated, namely chIFITM1, chIFITM3, chIFITM5 and chIFITM10 [50]. Although not 
yet annotated in the Gallus gallus reference sequence, studies show the existence of chIFITM2 and suggest a hypothetical genetic structure of the locus based on the human syntenic genome region [51]. The mammalian IFITM proteins are relatively small (about 130 amino acids) [33] and share a topology defined by a conserved CD225 domain, consisting of two intramembrane (IM) regions and a conserved intracellular loop (CIL) [52]. The chIFITMs show significant sequence divergence from mammals, and as such their topology is less well defined. The unique ability of IFITMs to inhibit viral entry into the host cell highlights their importance in innate immunity; by preventing cell entry, they subsequently prevent viral replication and disease [53].

Despite the progress in understanding the IFITM-mediated antiviral capacity, host chIFITM expression and viral restriction profiles in response to IBV infection have yet to be elucidated.

In this study, we observed significant changes in the transcriptional levels of chIFITMs in vivo, in vitro and ex vivo, after infection with three strains of IBV that vary in pathogenicity and tissue tropism, suggesting a potential role in the early defense against IBV infection.

\section{Materials and Methods}

\subsection{Ethics Statement}

All animal experiments have been published previously [54,55] and were carried out following the UK Home Office guidelines and the UK Animals (Scientific Procedures) Act 1986. All experiments were performed at The Pirbright Institute animal facilities, license number X24684464.

\subsection{Viruses and Cells}

The IBV strains used were (i) the pathogenic M41-CK strain (GenBank accession number MK728875.1), derived from the pathogenic M41 strain after multiple passages in primary chick kidney (CK) cells and displays classical respiratory disease [56]; (ii) the nonpathogenic recombinant laboratory strain Beau-R (GenBank accession number AJ311317), a molecular clone of CK cell-culture-adapted Beaudette strain [5]; (iii) the nephropathogenic QX strain (GenBank accession number KY933090). We also used a QX-like strain, D388 [57], for in vitro studies as QX exhibits limited tropism and does not infect DF-1 cells. The M41-CK isolate is able to produce infectious virions in CK cells but not in DF-1 cells, while Beau-R exhibits extended cell tropism and is able to produce infectious virions in both cell types $[5,18,58]$. The QX strain is not able to produce infectious virions in either chicken fibroblast cell line, DF-1 or CK cells [59]. All viruses were propagated in embryonated hen's eggs and quantified via titration in triplicate in either CK cells [60-62] or ex vivo tracheal organ cultures (TOCs) as described by [20]. Titers are displayed as the number of plaque-forming units (PFU) per $\mathrm{mL}$ or as a $50 \%$ (median) ciliostatic dose $\left(\mathrm{CD}_{50}\right)$ per $\mathrm{mL}$.

Primary CK cells were produced by the Central Services Unit (CSU) at The Pirbright Institute (TPI). CK cells were prepared from kidneys extracted from three-week-old specific pathogen-free (SPF) Rhode Island Red (RIR) chickens following a method previously described by [63]. DF-1 (immortalized chicken embryo fibroblast cell line) cells were obtained from CSU at TPI. All cell cultures were maintained at $37^{\circ} \mathrm{C}$ and $5 \% \mathrm{CO}_{2}$. Chickens were hatched and reared at TPI. Tracheal organ cultures were prepared from 19-day-old RIR SPF embryos as described by [64]. Cultures were maintained at $37^{\circ} \mathrm{C}$, rotating at $7-8$ revolutions per hour.

\subsection{Virus Infection In Vivo}

The tissues used for the in vivo analysis of this study were harvested as part of two previously described studies thereby incorporating the principles of the 3Rs: Replacement, Reduction and Refinement.

Briefly, in the first study, groups of 24 8-day old SPF RIR chickens were inoculated with either phosphate-buffered saline (PBS) (mock) or $10^{5}$ plaque-forming units (PFU) of either nonpathogenic recombinant (rIBV) Beau-R or pathogenic IBV, M41-CK. Clinical signs, including snicking and rales, 
were assessed from 1 to 7 days post-infection (dpi). Snicks were individually counted by two persons over a two-minute period and birds were checked individually for the presence of tracheal rales. On 1 , 4, 6 and 7 dpi, 6 randomly selected birds were euthanized by cervical dislocation and trachea tissue harvested. Ciliary activity in the trachea was assessed on 4 and 6 dpi [55]. Tracheal ciliary activity is used as the gold standard to determine the pathogenicity of an IBV strain [65], a ciliary activity score of less than $50 \%$ is deemed pathogenic. The clinical signs and ciliary activity have previously been reported [55].

In the second study, groups of 30 8-day old SPF RIR chicks were vaccinated with PBS via the intraocular and intranasal route [54]. Three weeks postvaccination chickens were challenged, via the same route of administration with either PBS, $10^{5}$ PFU M41-CK, or $10^{2.73} \mathrm{CD}_{50}$ nephropathogenic strain QX. Two, 4- and 14-days post-challenge, 5 birds were euthanized by cervical dislocation and a panel of tissues harvested, of which we used trachea and kidney for the present study. Kidney tissue was not harvested at $14 \mathrm{dpi}$. Clinical signs were assessed from days 2 to 8 post-challenge, and then on day 14. Ciliary activity was measured at day 4 post-infection. The clinical signs and ciliary activity have previously been reported [54]. A schematic overview of both study designs can be found in the supplementary data (Supplementary Figure S1). All tissue samples were stored at $-80{ }^{\circ} \mathrm{C}$ in RNAlater solution.

\subsection{Virus Infection In Vitro}

Confluent CK cells seeded in 12-well plates were infected with $1 \times 10^{6} \mathrm{PFU} / \mathrm{mL}$ of Beau-R, M41-CK or D388 (MOI = 1), or mock infected with sterile PBS and incubated at $37{ }^{\circ} \mathrm{C}$ and $5 \% \mathrm{CO}_{2}$ for 1 $\mathrm{h}$ before washing with PBS and replacing with $1 \mathrm{~mL}$ maintenance media containing $20 \mathrm{mM} \mathrm{BES}$ (N,N-Bis(2-hydroxyethyl)-2aminoethanesulphonic acid) (Sigma, St Louis, MO, USA, purity $\geq 99 \%$ ), 1X Eagle's Minimum Essential Medium (EMEM), 10\% TPB (Tryptose Phosphate Broth, 0.2\% Bovine Serum Albumin (BSA); 0.21\% sodium bicarbonate, $2 \mathrm{mM}$ L-glutamine, $50 \mathrm{U} / \mathrm{mL}$ nystatin, $10 \mathrm{U} / \mathrm{mL}$ penicillin and $10 \mu \mathrm{g} / \mathrm{mL}$ streptomycin. The BES is filtered sterilized before being incorporated into the medium [66].

DF-1 cells were infected with Beau-R $(\mathrm{MOI}=1)$ or mock infected with sterile PBS and incubated at $37^{\circ} \mathrm{C}$ and $5 \% \mathrm{CO}_{2}$ for $1 \mathrm{~h}$ before washing with PBS and replacing with $1 \mathrm{~mL}$ maintenance media. Total cellular RNA was extracted from CKC and DF-1 cell lysates harvested at 12, 24 and 36 and 6, 12, 24, 36 and 48 hours post infection (hpi) respectively. Viral supernatants were obtained and viral titers were determined by standard plaque assay in CK cells.

\subsection{Virus Infection in Ex Vivo Tracheal Organ Cultures (TOCs)}

TOCs were prepared from 2- to 3-week-old RIR SPF chickens. TOCs (one tracheal ring per tube) were infected 4 days after preparation to allow the early inflammatory responses of the tissue to subside [24,67]. TOCs were infected for one hour with either $1 \times 10^{5} \mathrm{PFU} / \mathrm{mL}$ Beau-R or M41-CK, or with $10^{2.73} \mathrm{CD}_{50} \mathrm{QX}$ and $10^{2.73} \mathrm{M} 41-\mathrm{CK}$, or mock infected with TOC medium without virus. TOC rings and supernatant were harvested at 2,4 and $8 \mathrm{hpi}$ and stored at $-80^{\circ} \mathrm{C}$. This experiment was performed in duplicate. The viral titer from harvested inoculum from Beau-R- and M41-CK-infected TOCs was determined by plaque assay titration on primary CK cells. The harvested inoculum from IBV M41-CK and QX strains were titrated in ex vivo TOCS [20] due to the restricted tropism of the QX strain.

\subsection{Total RNA Extraction and Two-Step Reverse Transcription}

Total RNA from tissue samples and cell pellets were extracted using the RNeasy Kit (Qiagen, Manchester, UK) following the manufacturer's instructions (for RNA extraction from animal tissues and animal cells) and included an on-column DNAse treatment step using the Rnase-free Dnase kit (Qiagen, Manchester, UK). RNA concentration was quantified by Nanodrop (Thermo Scientific). One $\mu \mathrm{g}$ of RNA was reverse transcribed into cDNA using SuperScript III First-Strand cDNA synthesis with random primers following the manufacturer's instructions. The cDNA concentration 
of each sample was normalized to $100 \mathrm{ng} / \mu \mathrm{L}$ in nuclease-free water for all quantitative reverse transcription PCR reactions. The presence of IBV was tested in all RNA samples using primers BG-56 (5'-CAACAGCGCCCAAAGAAG-3') and 93/100 (5'-GCTCTAACTCTATACTAGCCT-3') that target the $3^{\prime}$ untranslated region (UTR) of each IBV strain. PCR amplicons were run on a $2 \%$ gel and run for 1 $\mathrm{h}$ at $120 \mathrm{~V}$. These oligonucleotides can discriminate between the $3^{\prime}$ UTRs from Beau-R and M41-CK derived sequences. The $3^{\prime}$ UTR of QX and Beau-R results in a $667 \mathrm{bp}$ product but a $483 \mathrm{bp}$ PCR from M41-CK due to a $184 \mathrm{nt}$ deletion in the M41 3' UTR [68].

\subsection{Quantification of Virus Subgenomic RNA (sgRNA) in Infected Tissues, Cells and TOCs}

Viral RNA load was quantified by qRT-PCR using Taqman Fast Universal PCR $2 \times$ Master Mix and including $125 \mathrm{nM}$ final probe and $500 \mathrm{nM}$ final primers. These primers and probe (taken from [69]) specifically target the IBV N message (sgRNA) of Beau-R, M41-CK and QX IBV strains (one bp mismatch in reverse primer for QX strain still successfully and specifically amplified the QX sgRNA). Leader Forward Primer: 5'-CTAGCCTTGCGCTAGATTTTTAACT-3'; N sgRNA Reverse Primer 5'-GAGAGGTACACGCGGGACAA-3'; IBV sgRNA probe 5'-FAM-ACAAAGCAGGACA AGCA-MGB-NFQ-3'. Absolute quantitation of IBV RNA copy numbers was performed using standard curves generated by a serial dilution of plasmids. The $\mathrm{C}_{\mathrm{T}}$ results were used to calculate the log RNA copies $\left(\log _{10}\right)$ using the linear equation from the standard curve.

\subsection{IFITM Gene Expression Analysis}

Primer and probe assays to specifically target each of the chIFITM genes were designed by Primerdesign. Briefly, $1 \mu \mathrm{L}$ of the chIFITM assay was added to $5 \mu \mathrm{L}$ Taqman Fast Universal PCR $2 \times$ Master Mix, $2 \mu \mathrm{L}$ ddH20 and $2 \mu \mathrm{L}$ cDNA. The cycling conditions were 10 min at $95^{\circ} \mathrm{C}, 35$ cycles of $10 \mathrm{~s}$ at $95^{\circ} \mathrm{C}, 10 \mathrm{~s}$ at $60^{\circ} \mathrm{C}$ annealing temperature and $10 \mathrm{~s}$ at $75^{\circ} \mathrm{C}$. qRT-PCR data were normalized using two housekeeping genes, RPLPO and RPL13 [70]. Data are presented as the fold change in relative mRNA gene expression of virus-infected versus mock-infected samples. Analysis was performed using the relative quantification of gene expression $\left(\Delta \Delta C_{T}\right.$, where $C_{T}$ is the cycle threshold) using the QuantStudio 5 software. The target genes were compared to these two housekeeping genes individually and the $\Delta \Delta C_{T}$ averaged. The data were analyzed in GraphPad Prism using one-way ANOVA. ANOVA data were corrected for multiple comparisons using the Bonferroni adjustment method. Differences between groups at that time point were considered significant at $p<0.05$.

\section{Results}

\subsection{Clinical Observation}

In the first study, mock-infected birds and those infected with rIBV Beau-R, a molecular clone of the pathogenic Beau-CK strain [5], displayed no IBV-related clinical signs and no reduction in ciliary activity while birds infected with M41-CK displayed clinical signs from day 2 post-inoculation and had a reduced ciliary activity $(<2 \%)$, as previously described in [55].

In the second study, both QX-and M41-CK-infected birds exhibited IB-related symptoms, including snicking and rales, and reduction in ciliary activity as previously described [54]. The reduction in ciliary activity and the observed clinical signs further confirms the in vivo pathogenic phenotype of both these IBV strains [54].

\subsection{Transcriptional Profile of chIFITMs In Vivo}

To determine whether IBV infection induces chIFITM expression in vivo, tissues from chickens infected with three strains of IBV of different pathogenicities, were investigated; the apathogenic attenuated Beau-R strain, pathogenic laboratory M41-CK strain and the nephropathogenic QX strain were compared. The relative mRNA expression of IFN- $\alpha$, IFN- $\beta$, chIFITM1, 2, 3 and 5 as well as $M x$ was measured via qRT-PCR using cDNA originating from the RNA extracted from infected tissue. 
$M x$, a gene that is highly upregulated in response to viral infection, was used as a positive control for all qPCR experiments.

We did not detect any viral replication of Beau- $R$ in infected trachea; the Beau- $R$ genome copy number in the infected trachea was comparable to levels observed in mock-infected samples (Figure 1A). The absence of replicating Beau- $\mathrm{R}$ in the trachea supports what has been seen in previous studies $[20,69,71]$. Infection with Beau-R did not elicit an upregulation of either IFN- $\alpha$, IFN- $\beta$ or chIFITMs mRNA in infected trachea (Figure 1B-G), strengthening the assumption that Beau-R fails to produce a productive infection in vivo [55]. In the trachea of chickens infected with M41-CK, the viral copy number was significantly higher when compared to mock-infected and Beau-R-infected samples, peaking at $4 \mathrm{dpi}\left(9.8 \times 10^{4} \pm 1.5 \times 10^{5}\right.$ copies $\left./ \mu \mathrm{L} ; p=0.017\right)$, steadily decreasing until $7 \mathrm{dpi}$ $\left(1.28 \times 10^{2} \pm 2.7 \times 10^{1}\right.$ copies $\left./ \mu \mathrm{L}\right)$ (Figure 1A). In the M41-CK-infected trachea, both IFN- $\alpha$ and IFN- $\beta$ are significantly upregulated, with relative mRNA expression peaking at 4 dpi for both (Figure 1B,C, respectively), consistent with IBV replication which also peaks at 4 dpi. chIFITM1, 2 and 3 are significantly upregulated at $1 \mathrm{dpi}$ and at $4 \mathrm{dpi}$, decreasing until levels are comparable to that observed in mock-infected samples at 7 dpi (Figure 1D-F). The upregulation of chIFITM5 was only significantly upregulated in comparison to mock- and Beau-R-infected trachea at $4 \mathrm{dpi}$ (Figure 1G). Due to the observation that Beau-R does not produce a productive infection in vivo, and therefore does not elicit an interferon or a chIFITM response, a nephropathogenic strain of IBV, QX, was included in the analysis. This enables a valuable comparison of chIFITM response in IBV strains of varying pathogenicities.
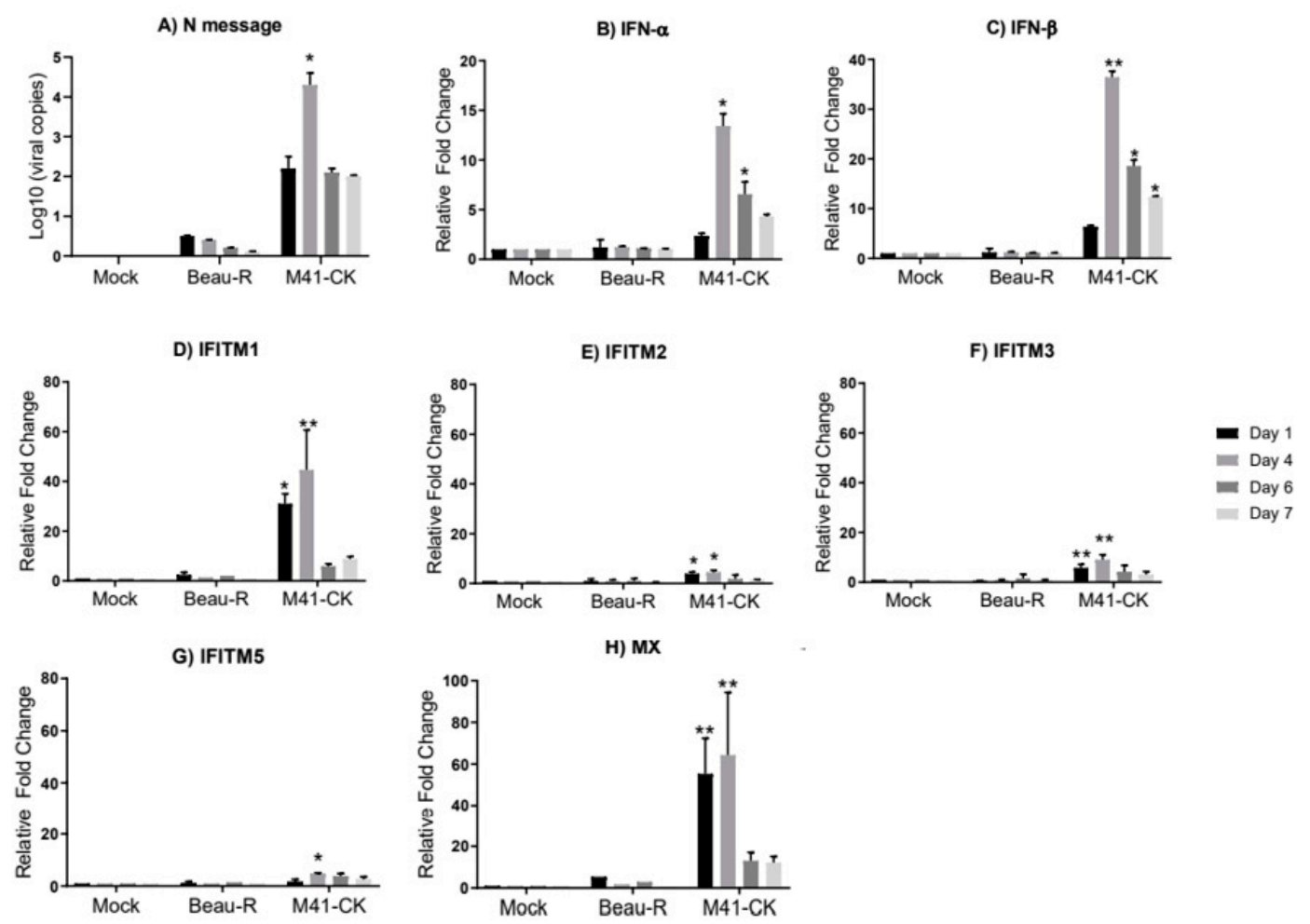

Figure 1. Expression of IFNs and chIFITMs are upregulated in the trachea of chickens in response to M41-CK infection but not to Beau-R infection. (A) $\log _{10}$ of infectious bronchitis virus (IBV) RNA copies in tracheas from chickens infected with Beau-R and M41-CK. The IBV genome loads were determined using absolute quantification. Relative mRNA expression of (B) IFN- $\alpha,(\mathbf{C}) \operatorname{IFN}-\beta,(\mathbf{D}-\mathbf{G})$ chIFITM1, 2, 3 and 5 and (H) $M x$ in trachea from chickens infected with pathogenic M41-CK and nonpathogenic Beau-R strain of IBV were analyzed for gene expression at 1, 4, 6 and 7 days post infection (dpi). Relative mRNA expression was determined by real-time PCR normalized to two reference genes RPLPO and RPL13. All graph values are the mean of three biological replicates with error bars as standard deviation; * indicates $p<0.05,{ }^{* *}$ indicates $p<0.01$ ANOVA data were corrected for multiple comparisons using the Bonferroni adjustment method (GraphPad). 
In the comparison of M41-CK and QX IBV strains, we observed active replication of the virus in the trachea of infected chickens (Figure 2A). IBV-derived RNA was detectable as early as 2 dpi. The viral load for M41-CK and QX peaked at $4 \mathrm{dpi}\left(5.3 \times 10^{4} \pm 8.6 \times 10^{3}\right.$ and $\left.4.3 \times 10^{3} \pm 6.2 \times 10^{3}\right)$, respectively, and by $14 \mathrm{dpi}$, only low levels of replicating virus were observed. The viral load in the trachea detected in this study is comparable to the relative viral load detected by Ellis et al. [54].
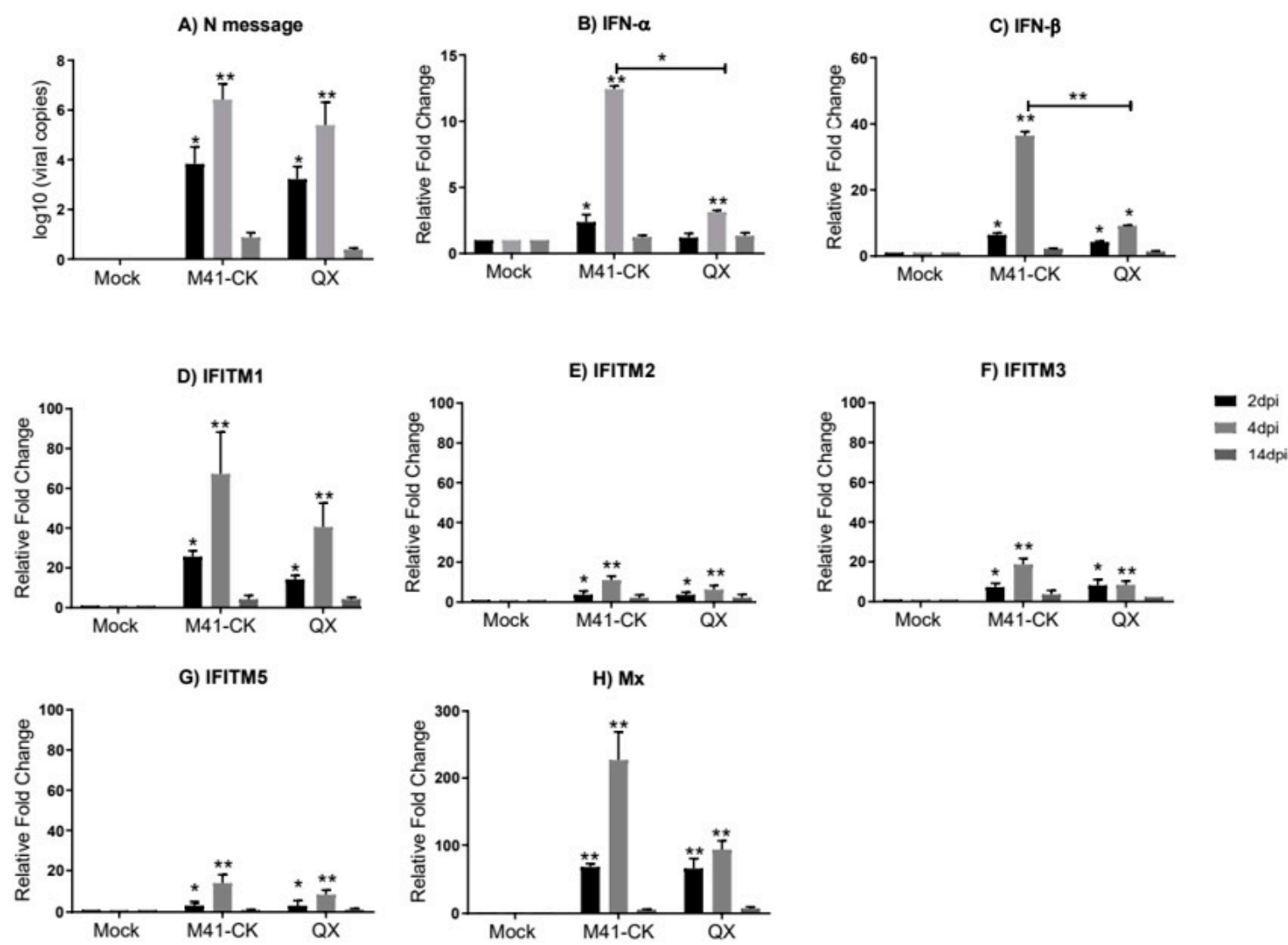

Figure 2. Relative expression of IFNs and chIFITMs in trachea samples from chickens infected with M41-CK and the nephropathogenic QX strain. (A) $\log _{10}$ of IBV RNA copies in trachea from chickens infected with pathogenic M41-CK or nephropathogenic QX, or mock infected, measured at 2, 4 and 14 dpi. Relative expression of (B) IFN- $\alpha$, (C) IFN- $\beta$ and (D-G) ChIFITM1, 2, 3 and 5 and (H) Mx measured by qRT-PCR in tracheal samples collected at 2, 4 and 14 dpi from chickens experimentally challenged with M41-CK and QX IBV, or mock infected. Relative fold change was calculated using the $\triangle \Delta C T$ equation, relative to mock and normalized to two reference genes, RPLPO and RPL13. All graph values are the mean of three biological replicates with error bars as standard deviation. ${ }^{*}$ indicates $p<0.05$, ** indicates $p<0.01$. ANOVA data were corrected for multiple comparisons using the Bonferroni adjustment method (GraphPad).

In trachea from M41-CK- and QX-infected chickens, although significantly upregulated as early as $2 \mathrm{dpi}$, the relative expression of IFN- $\alpha$, IFN- $\beta$ and chIFITM1, 2, 3 and 5 peaks at 4 dpi (Figure 2B-G). This significant induction of immune genes is consistent with IBV replication which peaks at 4 dpi in infected trachea (Figure 2A). IFN- $\alpha$ and IFN- $\beta$ both display significantly higher mRNA expression in M41-CK-infected trachea when compared to QX-infected trachea $\left(p\right.$-value $=5.4 \times 10^{-2}$ and $4.21 \times 10^{-3}$, respectively). The chIFITM genes display a similar pattern of expression in M41-CK- and QX-infected trachea; the highest and most significant upregulation of chIFITM mRNA expression was observed at $4 \mathrm{dpi}$ and had decreased by $14 \mathrm{dpi}$ where the levels of gene expression were comparable to mock-infected samples. The upregulation of chIFITM1 was the largest in both M41-CK- and QX-infected trachea (fold change $>70$ and $>40$, respectively) (Figure 3D), followed by chIFITM3 (fold change $>18$ and $>7$, 
respectively) (Figure 2F), chIFITM5 (fold change $>14$ and $>8$, respectively) (Figure 2G) and chIFITM2 (fold change $>12$ and $>6$, respectively) (Figure 2E). Overall, the mRNA expression of each chIFITM was higher in M41-CK-infected tissues when compared to QX, however, this difference was not statistically significant. We observed similar levels and patterns of IFN and chIFITM expression in M41-CK-infected trachea from both studies (Figures 1 and 2).

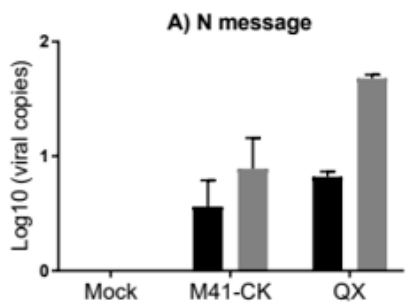

D) IFITM1

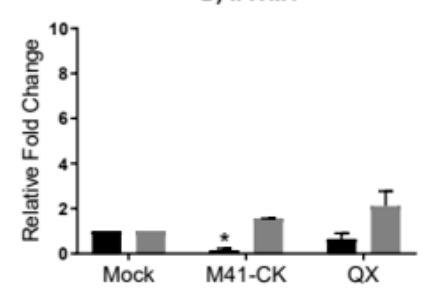

G) IFITM5

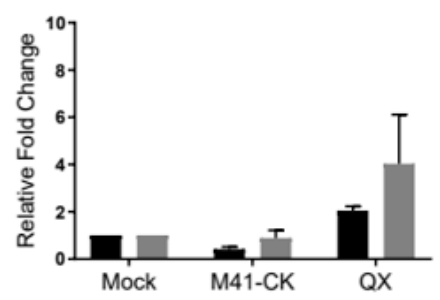

B) IFN- $\alpha$

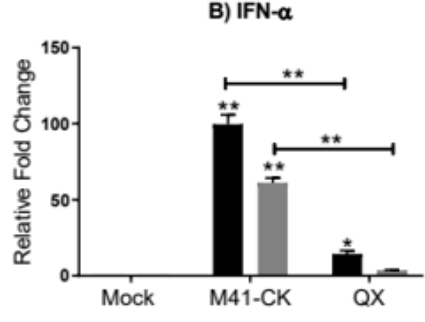

E) IFITM2

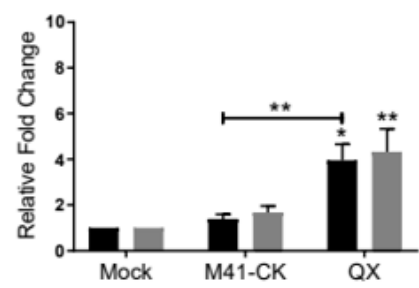

H) $M X$

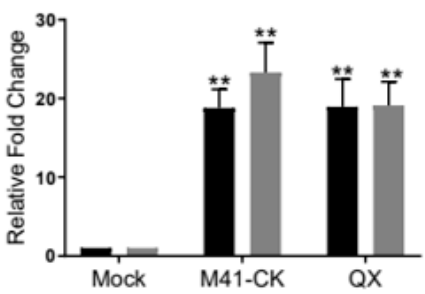

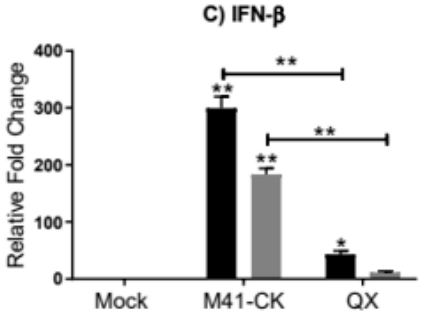

F) IFITM3

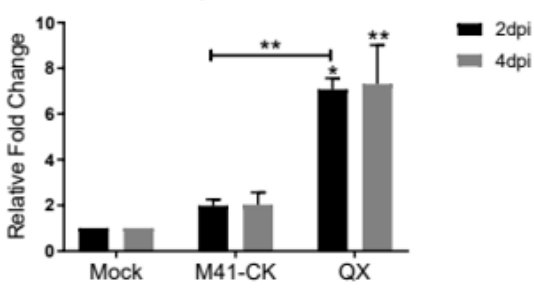

Figure 3. Relative expression of chIFITMs and IFNs in kidney samples from chickens infected with M41-CK and the nephropathogenic QX strain. (A) $\log _{10}$ of IBV RNA copies in the kidney from chickens infected with pathogenic M41-CK or nephropathogenic QX, or mock infected, measured at 2 and $4 \mathrm{dpi}$. Relative expression of (B) IFN- $\alpha$, (C) IFN- $\beta$ and (D-G) chIFITM1, 2, 3 and 5 and (H) $M x$ measured by qRT-PCR in kidney samples collected at 2 and 4 dpi from chickens experimentally challenged with M41-CK and QX IBV, or mock infected. Relative fold change was calculated using the $\triangle \triangle C T$ equation, relative to mock and normalized to two reference genes, RPLPO and RPL13. All graph values are the mean of three biological replicates with error bars as standard deviation. * indicates $p<0.05,{ }^{* *}$ indicates $p<0.01$. ANOVA data were corrected for multiple comparisons using the Bonferroni adjustment method (GraphPad).

In the kidneys of chickens in the same group (kidney samples taken at 2 and 4 dpi only), we only observe low levels of replicating M41-CK at both 2 and 4 dpi ( $\log _{10}$ M41-CK copies $0.1 \times 10$ and $0.15 \times 10$, respectively) (Figure $3 \mathrm{~A})$. For QX the viral load was low at $2 \mathrm{dpi}(0.8 \times 10)$ but had increased slightly by $4 \mathrm{dpi}\left(1.68 \times 10^{2}\right)$; however, levels were still not significantly different to those of mock-infected samples. We believe that these time points sampled were too early to detect large levels of replicating virus in the kidney. We observe a strikingly different pattern of IFN and chIFITM mRNA expression in the kidney when compared to the trachea. The relative mRNA expression of IFN- $\alpha$ (Figure 3B) and IFN- $\beta$ (Figure 3C) is higher in the kidney when compared to the trachea, and in the kidney, we observe low levels of chIFITM expression when compared to expression levels observed in the trachea (Figure 3D-G and Supplementary Figure S2). At 2 dpi, we observe a higher expression of chIFITM2 and 3 in kidneys from QX-infected chickens when compared to M41-CK-infected chicken kidney samples. 
chIFITM1, which exhibited the largest upregulation in the trachea, is only slightly elevated in kidney samples from M41-CK- and QX-infected chickens at 2 dpi (Figure 3D). The expression of chIFITM1 and chIFITM5 (Figure 3G) is downregulated in kidneys from M41-CK-infected chickens at 2 dpi but expression increases by $4 \mathrm{dpi}$. There was no downregulation of any chIFITM observed in the trachea. ChIFITM2 and 3 mRNA expression is significantly higher in the kidney from QX-infected chickens at 2 dpi and 4 dpi when compared to mock-infected samples but not significantly different to samples from M41-CK-infected chickens (Figure 3E,F, respectively). Levels of $M x$ mRNA expression was similar between M41-CK- and QX-infected chickens' kidney samples and significantly upregulated in comparison to mock-infected samples at 2 and $4 \mathrm{dpi}$ (Figure $3 \mathrm{H}$ ). The upregulation of IFN- $\alpha$ and IFN- $\beta$ expression in kidney is high even though the viral titers are low. Therefore, we no longer see any correlation between IFN expression and viral load in the kidney like we had observed in the trachea. However, the relative mRNA expression of the chIFITMs in the kidney is low, consistent with the low levels of viral load detected in the kidney.

\subsection{Transcriptional Profiles of chIFITMs in Ex Vivo TOCs}

To comprehensively examine IFITM expression in response to IBV an in vitro model would be beneficial. However, both M41-CK and QX have restricted tropism in vitro, with M41-CK only able to propagate in primary $C K$ cells. The $S$ gene of Beau-R confers extended tropism to Beau-R, enabling it to replicate in DF-1 cells, Vero cells and BHK cells [18]. To determine whether Beau-R could be used to investigate IFITM expression in vitro, an ex vivo TOC model using time points of 2,4 and 8 hpi was established. Mirroring the two in vivo experiments, Beau-R and M41-CK were investigated, as well as M41-CK and QX. In the ex vivo TOCs, Beau-R does actively replicate as previously reported [66]. The Beau-R viral load steadily increased from $2 \mathrm{hpi}\left(0.5 \log _{10}\right)$ to $8 \mathrm{hpi}\left(2.03 \log _{10}\right)$ and the M41-CK viral load also increased from 2 hpi $\left(0.7 \log _{10}\right)$ to $8 \mathrm{hpi}\left(4.2 \log _{10}\right)$ (Supplementary Figure S3A). Beau-R and M41-CK viral titers detected at 8 hpi were $603 \mathrm{PFU} / \mathrm{mL}$ and $1400 \mathrm{PFU} / \mathrm{mL}$, respectively, (Supplementary Figure S3B). The viral load in Beau-R- and M41-CK-infected TOCs were significantly higher when compared to mock-infected samples at each time point; 2 hpi ( $p=0.04$ and $p=0.002$, respectively), 4 hpi $(p=0.02$ and $p=0.003$, respectively) and $8 \mathrm{hpi}(p=0.01$ and $p=0.009$, respectively). Supplementary Figure S3C shows the significant increase in viral load (compared to mock-infected samples) from 2 hpi to 8 hpi for M41-CK and QX strains ( 2 hpi; $p=0.04$ and $p=0.03$, respectively, 4 hpi; $p=0.02$ and $p=0.003$, respectively, and $8 \mathrm{hpi} ; p=0.01$ and $p=0.009$, respectively). A slightly higher increase for the nephropathogenic QX strain was detected when compared to the less pathogenic respiratory M41 strain observed in infected TOCs. The infectivity titer measured as ciliostatic dose $\left(\mathrm{CD}_{50}\right)$ at 8 hpi was 2.3 for M41-CK $(p=0.006)$ and 1.98 for QX $(p=0.001)$ (Supplementary Figure S3D). The $\log _{10}$ viral copies of M41-CK at $8 \mathrm{hpi}$ in Study 1 is comparable to the $\log _{10}$ viral copies of this virus at 8 hpi in Study $2(4.2 \times 10$ and $3.9 \times 10$, respectively).

We also show there is a higher level of relative mRNA expression of each chIFITM in TOCs infected with Beau-R, M41-CK or QX when compared to mock-infected TOCs. However, these levels of expression do not reach levels of statistical significance (Supplementary Figure S4). For each chIFITM, the relative mRNA expression is higher in QX-infected TOCs when compared to both Beau-R- and M41-CK-infected TOCs; however, this difference is not significant. Regardless of IBV strain, the most upregulated chIFITM response in infected TOCs is at $2 \mathrm{hpi}$, which decreases by 4 and 8 hpi.

\subsection{Infectious Bronchitis Virus Infection Induces chIFITM Expression In Vitro}

To determine whether IBV infection induces chIFITM expression in vitro, CK cells were infected over a $36 \mathrm{~h}$ period with the same Beau-R and M41-CK IBV isolates used in the in vivo study. However, the QX strain used for the in vivo experiments cannot be propagated in vitro, therefore the nephropathogenic QX-like strain, D388 [26] was used. For each IBV strain used to infect the CK cells, we observe a steady increase in the viral load from 12 to 36 hpi (Figure 4A). Expression of IFN- $\alpha$, IFN- $\beta$, and the chicken IFITMs (chIFITM1, 2 and 3 but not 5) (Figure 4B-G) are significantly upregulated in 
response to IBV infection in CK cells. The expression of each chIFITM as well as IFN- $\alpha$ and IFN- $\beta$ in CK cells infected with the two pathogenic IBV strains, M41-CK and D388, although only moderately upregulated, is significantly higher than what we observe in mock-infected cells. This upregulated expression appears to gradually increase from 12 to $36 \mathrm{hpi}$. However, the expression of the IFNs and chIFITMs are upregulated at $36 \mathrm{hpi}$ in CK cells infected with the apathogenic Beau-R strain. Because this increased expression from $24 \mathrm{hpi}$ to $36 \mathrm{hpi}$ is so large, it appears that the upregulation of IFNs and IFITMs in Beau-R-infected cells is delayed. In CK cells, the expression of the immune genes are maximal at $36 \mathrm{hpi}$, consistent with the viral load, which also peaks at $36 \mathrm{hpi}$.

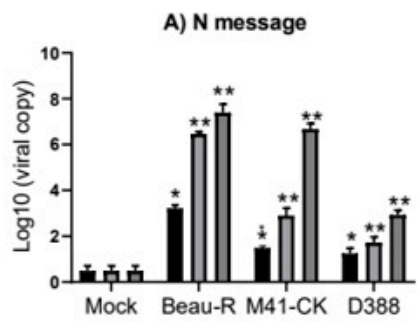

D) IFITM1

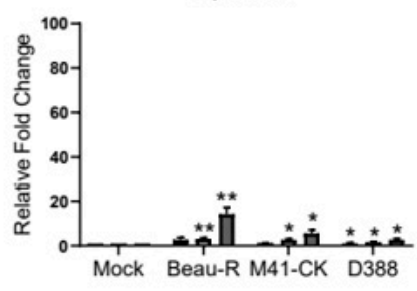

G) IFITM5

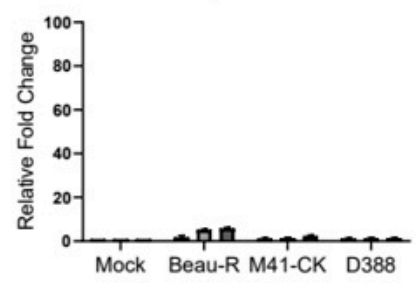

B) IFN- $\alpha$

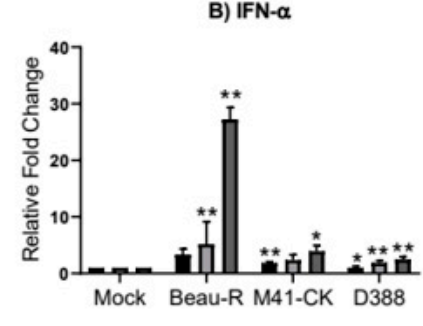

E) IFITM 2

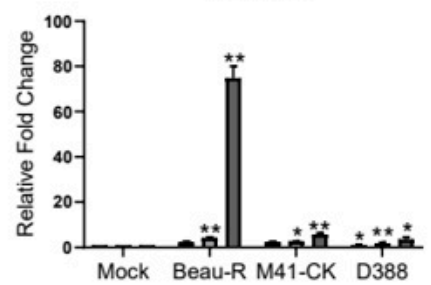

H) $M x$

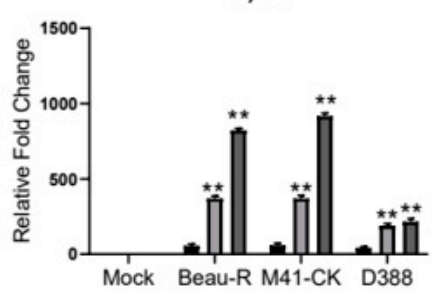

C) IFN- $\beta$

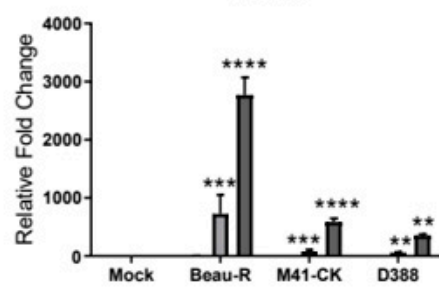

F) IFITM3

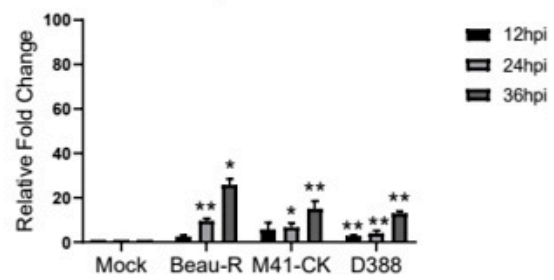

Figure 4. Infection of chick kidney (CK) cells with Beau-R, M41-CK and D388 upregulates the expression of the chIFITMs and IFNs. (A) Replicating virus detected by qRT-PCR using primers and a probe specific for IBV N message. The expression level and log fold change of (B) IFN- $\alpha,(\mathbf{C})$ IFN- $\beta,(\mathbf{D}-\mathrm{G})$ chIFITM1, 2, 3 and 5 and (H) Mx were measured using qRT-PCR after infection with Beau-R, M41-CK or D388 (MOI 1) in CK cells normalized to RPL13 and RPLPO housekeeping genes. Error bars show standard deviations of the means $(n=3)$, * indicates $p<0.05$, ** indicates $p<0.01$, *** indicates $p<0.001$, $* * * *$ indicates $p<0.0001$. ANOVA data were corrected for multiple comparisons using the Bonferroni adjustment method (GraphPad).

We also employed a chicken DF-1 cell line as a model system to further investigate the interaction between host innate immune system and IBV and the role of IFITMs in defense against viral infection. These further experiments were only performed using Beau-R because the cell tropism of both M41-CK and QX is constrained, limiting their infection to primary CK cultures, which are not suitable for transfection experiments.

In DF-1 cells, we observe a steady increase in the viral load from 6 to 48 hpi (Figure 5A). The relative mRNA expression of IFN- $\alpha$ and IFN- $\beta$ were greatly upregulated by Beau-R infection, displaying a substantial increase from 6 to 48 hpi (Figure 5B,C respectively). In comparison to IFN- $\alpha$, which is significantly upregulated by $12 \mathrm{hpi}$, IFN- $\beta$ appears to have a delayed response with mRNA levels remaining low until $24 \mathrm{hpi}$, after which it is strongly upregulated reaching 350-fold at $48 \mathrm{hpi}$. ChIFITM2 and 3 were highly upregulated by 120-fold and 130-fold at 48 hpi (Figure 5E,F, respectively). 
The expression of chIFITM1 (Figure 5D) was upregulated in response to Beau-R infection but only reached levels of significance at 48 hpi. Although chIFITM5 (Figure 5G) expression was upregulated in response to Beau-R infection, this upregulation did not reach levels of significance. Immune gene expression peaks at $48 \mathrm{hpi}$, which is consistent with the viral load, which also peaks at $48 \mathrm{hpi}$.

A) $\mathbf{N}$ message

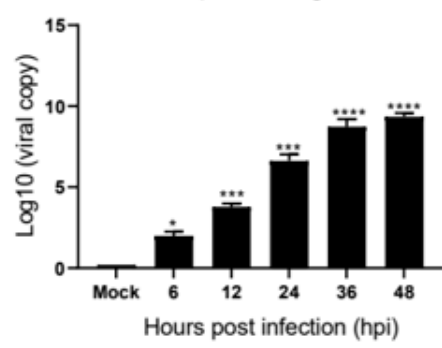

D) IFITM1

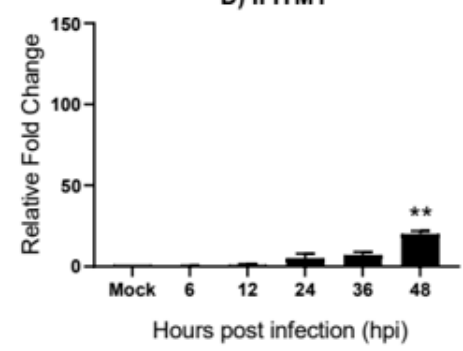

G) IFITM5

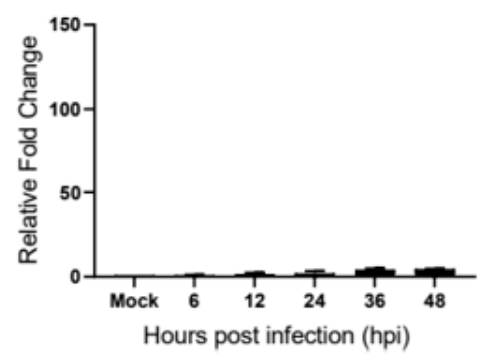

B) IFN- $\alpha$

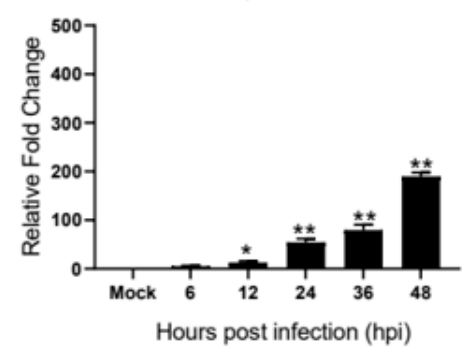

E) IFITM2

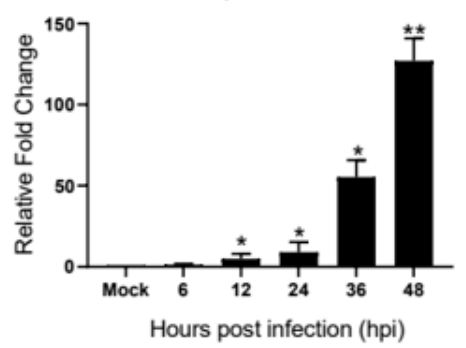

H) $\mathrm{Mx}$

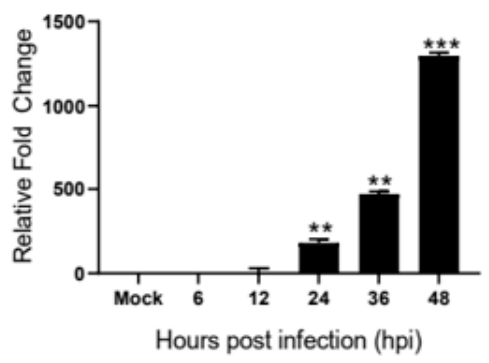

C) IFN- $\beta$

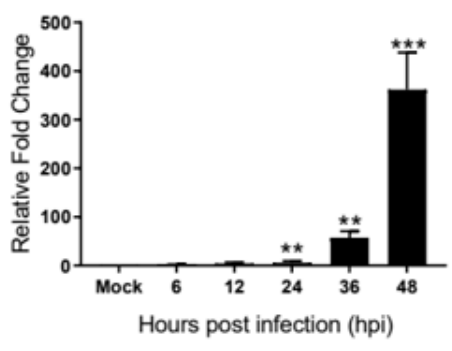

F) IFITM3

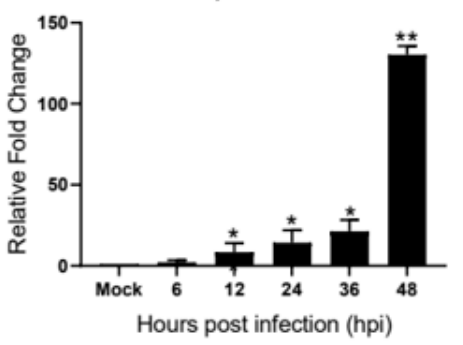

Figure 5. chIFITM1, 2, 3 and IFNs are significantly induced in DF-1 cells after Beau-R infection DF-1 cells were infected with MOI of 1 of Beau-R and harvested at 6, 12, 24, 36 and 48 hpi, respectively. (A) Replicating virus detected by qRT-PCR using primers and a probe specific for the N message of Beau-R. qRT-PCR was performed to determine the relative mRNA expression of (B) IFN- $\alpha,(\mathbf{C})$ IFN- $\beta$, (D-G) chIFITM1, 2, 3, and 5 and (H) Mx compared to mock-infected cells. Relative fold change was calculated using the $\triangle \triangle \mathrm{CT}$ equation, relative to mock and normalized to two reference genes, RPL13 and RPLPO. Error bars show standard deviations of the means $(\mathrm{n}=3)$. * indicates $p<0.05$; ** indicates $p<0.01 ;{ }^{* * *}$ indicates $p<0.001 ;{ }^{* * *}$ indicates $p<0.0001$. ANOVA data were corrected for multiple comparisons using the Bonferroni adjustment method (GraphPad).

\section{Discussion}

In this study, we found that key IFNs and immune-related IFITMs were significantly upregulated in response to IBV infection in vivo and in vitro. It is well known that IFITMs serve as critical effector molecules in the host innate immune system and are the first line of defense against invading viruses $[43,52,72]$. The IFN-induced expression of these genes indicates the initiation of the innate host response. These proteins play an important role in the control of infection by influenza [72,73]; respiratory syncytial virus (RSV) [74] as well as mammalian coronaviruses such as the highly pathogenic MERS-CoV [75] and SARS-CoV [38]. Wrensch and colleagues observed that the IFITM-mediated inhibition of cellular entry of SARS-CoV and MERS-CoV was less efficient than blocking the cellular 
entry of the globally circulating human coronaviruses 229E and NL63, highlighting the differential IFITM-sensitivity of coronaviruses [75]. It would be interesting to determine whether SARS-CoV-2 cell entry and replication is affected in any way by IFITM expression. In contrast, Zhao et al., have shown that human IFITM2 and IFITM3 are essential host factors that facilitate the cellular entry of human coronavirus OC43 [76]. The restrictive role of these proteins in the avian coronavirus, IBV, is less well defined. This study is the first to focus primarily on the response of chicken IFITMs during early phase infectious bronchitis viral infection, examining the relative mRNA expression profile of chIFITMs following IBV infection in vivo and in vitro.

We did not observe any significant upregulation of the chIFITMs (or IFNs) in the trachea taken from birds infected with the nonpathogenic Beau-R strain (Figure 1). There was also no detection of replicating virus in this tissue suggesting that Beau- $\mathrm{R}$ fails to consistently produce a productive infection in vivo. This finding is in line with data from other studies $[20,58,68]$. The pathogenic M41-CK and nephropathogenic QX strain both actively replicate in the trachea of infected chickens, as is evident by the high viral load detected in this tissue (Figure 2). Infection of chickens with M41-CK and QX strains elicits a significant upregulation of chIFITM1, 2, 3 and 5 in the trachea at 2 and 4 dpi. The expression levels of these chIFITMs, in both M41-CK and QX infection, were significantly higher than mock as early as $2 \mathrm{dpi}$, peaking at $4 \mathrm{dpi}$, after which they decreased, highlighting a possible role in early response against viral infection. The decrease in immune gene response over time could also be decreasing with the viral load as birds recover from the infection. Although each of the chIFITMs had a higher level of expression in the trachea infected with the less virulent M41-CK strain, the difference in gene expression levels between M41-CK and the more virulent QX, did not reach statistical significance. This may suggest that the magnitude of chIFITM response is not directly associated with virus pathogenicity, as infection with the more virulent QX strain elicits a smaller chIFITM response in the trachea (Figure 2). This observation may be explained by the specific tissue tropism of the different virus strains; M41-CK primarily targets the upper respiratory tract while the nephropathogenic QX exhibits a kidney tropism, therefore potentially eliciting a larger chIFITM response in this tissue (Figure 3). We observe a higher level of chIFITM expression in QX-infected kidney at 2 dpi in comparison to kidneys from M41-CK-infected birds. Therefore, chIFITM response may vary due to specific tissue tropism of the virus rather than differences in the pathogenicity of viral strains. These results could also highlight a tissue-specific response of chIFITMs, suggesting that tissue tropism may be a factor that influences chIFITM expression. In addition, we cannot rule out potential downregulation of the IFN response by the pathogenic strains of IBV.

We did not detect any M41-CK viral RNA in the kidney tissues sampled at 2 and/or 4 dpi (Figure 3A). This finding is not surprising, as published data suggests that M41 strains may not have the ability to disseminate through the mononuclear cells and plasma at that stage of infection [71], hence this strain is not classified as nephropathogenic. However, some studies have shown that M41 does reach the kidney at low levels, but only after $7 \mathrm{dpi}[77,78]$. This discrepancy between studies might be a result of variances in the experimental conditions and design, breed or age of the birds and/or the use of different isolates of M41. It is not yet known if the M41-CK isolates of IBV have the ability to infect the kidney in vivo, however, according to our data, we suggest that the absence of any upregulated chIFITM response in M41-CK-infected kidney tissue may be due to the fact that there is no virus detected in this tissue at the time points sampled. However, the possibility of the presence of M41-CK viral RNA in the kidney at later time points cannot be completely excluded as they were not sampled beyond $4 \mathrm{dpi}$ in this study. More surprisingly, we observe low levels of the nephropathogenic QX viral RNA in the infected kidney at $4 \mathrm{dpi}$. These levels are not significantly different to control samples. We believe that the time points sampled may have been too early to detect any productive replication of the virus in the kidneys. In the literature, replicating virus is only detected in the kidneys at or later than 5 dpi [79], 7 dpi [7], 9 dpi [23] and 12 dpi [71]. It is also possible that infection with QX leads to a systemic interferon response whereby tissues with a low viral load, like the kidney, are primed for infection by the initiation of interferon signaling. Although 
low, the levels of QX viral load detected at $4 \mathrm{dpi}$ is sufficient to elicit a significant upregulation of chIFITM2 and 3. The nephropathogenic QX strain and respiratory M41-CK strain have different tissue tropisms; however, both strains successfully replicate in the trachea. Therefore, in vivo, we do not see any correlation between virus pathogenicity with levels of chIFITM or IFN response, but we do observe a correlation with increasing viral load and immune gene expression.

Tracheal organ cultures (TOCs) have previously been used for examining viruses, including IBV within an in vitro environment $[80,81]$. Such studies have allowed for the comparison of strain virulence, analysis of infection mechanisms and virus neutralization. In the ex vivo TOC infection study (Supplementary Figures S3 and S4), we observed that all three strains of IBV tested actively replicated in the TOCs, whereas Beau-R did not replicate in the trachea in vivo. Lower infectious virus production was observed for M41-CK-infected TOCs compared to QX-infected TOCs; however, this difference did not reach levels of significance. Transcriptional regulation of chIFITMs in TOCs infected with M41-CK and QX strains was analyzed at $8 \mathrm{hpi}$. No significant upregulation of the IFITMs was detected, although chIFITM1 and 5 mRNA expression were markedly higher in M41-CK-infected TOCs. chIFITM expression is highest at 2 hpi followed by a steady decrease over time, suggesting the chIFITM response in the TOCs is not sustained as the viral load continues to increase over time. Therefore, in vivo, ex vivo as well as in vitro, we do not see any correlation between increasing viral load and/or the virus pathogenicity with levels of chIFITM response. This may suggest that chIFITM response may be due to viral entry.

One of the notable impediments in avian viral research is the relatively limited tissue tropism which affects the ability of avian viruses to infect cells in vitro. Therefore, it is not always possible to perform all in vitro experiments in the same cells because of the limited tropism of specific viral strains. This is a recognized issue with coronavirus IBV. In this study we were not able to assess the effect of QX infection on chIFITM expression in CK cells as QX does not infect these cells, however, the D388 strain does. D388 is a good substitute for in vitro work with QX because it produces very comparable disease in vivo and it is of the same genotype. In the in vitro studies, we observed that infection with Beau-R, M41-CK and D388 elicit significant upregulation of IFN- $\alpha$, IFN- $\beta$ and chIFITMs. Interferon and chIFITM gene response to M41-CK and D388 infection in CK cells displayed a gradual increase in expression from $12 \mathrm{hpi}$ to $36 \mathrm{hpi}$, with levels reaching statistical significance at 24 hpi while in Beau-R-infected CK cells, IFITM and IFN response is relatively low and at similar levels at 12 and $24 \mathrm{hpi}$ but an increased IFITM and IFN response is observed at $36 \mathrm{hpi}$. (Figure 4). A delayed response in immune genes has been observed in CK cells and DF-1 cells infected with apathogenic Beau-R in previous studies [82]. The observed variability in the magnitude of chIFITM mRNA expression between the different IBV strains suggests that chIFITM response to IBV infection may be strain-dependent, and tissue tropism may be an influencing factor. The nephropathogenic D388 strain elicits similar levels of chIFITM expression to the pathogenic M41-CK strain, while we see the greatest upregulation of IFN and chIFITMs in response to infection with the apathogenic Beau-R. This may suggest that virus pathogenicity does not play a significant role in chIFITM induction during the course of infection. However, Beau-R is a cell adapted strain that replicates much more efficiently than D388 and M41-CK in cell culture. In the M41-CK and D388 infection, results mirror the main findings from the in vivo study; however, the expression patterns of each chIFITM differs between the in vivo and in vitro studies. chIFITM1 is highly upregulated in trachea while only moderately upregulated in cells, while chIFITM2 and 3 are highly upregulated in cells and only moderately upregulated in trachea, highlighting the celland tissue-specific expression of this family of immune genes.

There appears to be a correlation between chIFITM expression and the presence of replicating virus in the tissues and cell types analyzed in this study. High viral loads are accompanied by high levels of chIFITM expression in the trachea, while low, almost undetectable levels of replicating virus in the kidney is accompanied by low levels of chIFITM mRNA. We do not observe the same kind of correlation for the IFNs, which demonstrate high levels of mRNA expression in the kidney when there is a negligible detectable replicating virus. Although this data cannot be supported by statistical 
analysis as the sample size was too small, it may suggest that the level of chIFITM expression may depend on the level of replicating virus.

In this study, we have shown that the level of chIFITM expression does not correlate with virus pathogenicity, but the varied expression of chIFITMs between the pathogenic and apathogenic strains in vitro may be due to the differences in the growth kinetics of the virus. Such variation may influence the level and pattern of chIFITM expression during the course of a specific strain of IBV infection. In addition, individual strains may encode specific mechanisms to evade the host immune system by directly or indirectly regulating the expression of host immune genes. The coronavirus accessory proteins in particular have been identified to have potential roles in mediating IFN responses as well as in host cell translation shut off [83-85]. All four accessory proteins have been implicated as pathogenicity factors [85]. Our data suggest chIFITMs expression peaks early in infection, regardless of the IBV strain. It is possible that chIFITMs play a role in the entry of IBV, which is comparable with what has been observed with other coronaviruses [69,71], and that IBV might be differentially restricted by IFITM proteins in a cell- and tissue-specific manner. In addition, it has been shown that basal levels of expression of immune genes will impact viral replication [84], and the basal level of expression of chIFITMs is known to vary among different cell and tissue types.

Therefore, we have revealed that IFITM-induced viral restriction appears to be cell-type- and tissue-dependent, in that the efficiency of entry inhibition by IFITM proteins may depend on the expression level in that specific cell and/or tissue.

\section{Conclusions}

We have shown that chIFITMs are significantly upregulated in response to IBV infection in vivo and in vitro. Taken together, IBV infection induces an effective host antiviral immune response involving the immune-related IFITM proteins, which may be useful for developing new antiviral drugs in the future.

Supplementary Materials: The following are available online at http://www.mdpi.com/2073-4425/11/8/918/s1, Figure S1: Schematic overview of the study design, Figure S2: Relative expression of IFNs and chIFITMs in trachea and kidney samples from chickens infected with M41-CK and the nephropathogenic QX strain, Figure S3: Characterization of Beau-R, M41-CK and QX in tracheal organ cultures (TOCs), Figure S4: Relative expression of chIFITMs in IBV infected TOCs.

Author Contributions: Conceptualization, A.S. and M.F.; methodology and laboratory work, A.S., and S.K.; data Analysis, A.S.; writing_-original draft preparation, A.S.; writing-review and editing, M.F., E.B., S.K. and funding acquisition, M.F. and E.B. All authors have read and agreed to the published version of the manuscript.

Funding: Study 1 of this project was funded by Biotechnology and Biological Science Research Council (BBSRC) strategic grants to The Pirbright Institute, BBS/E/I/00007031, BBS/E/I/00007034 and BBS/E/I/00007038. Study 2 was funded by BBSRC grant BB/M012794/1 in collaboration with Prof. Lonneke Vervelde at the Roslin Institute. The in vitro and ex vivo experiments were funded by BBSRC grants BBS/E/I/00007030 and BBS/E/I/00007031.

Acknowledgments: We are very grateful to Lonneke Vervelde and Samantha Sives née Ellis for sharing tissue samples harvested during Study 2 [64] with us for this investigation.

Conflicts of Interest: The authors declare no conflict of interest.

\section{References}

1. Fehr, A.R.; Perlman, S. Coronaviruses: An overview of their replication and pathogenesis. Methods Mol. Biol. 2015, 1282, 1-23.

2. Rota, P.A.; Oberste, M.S.; Monroe, S.S.; Nix, W.A.; Campagnoli, R.; Icenogle, J.P.; Penaranda, S.; Bankamp, B.; Maher, K.; Chen, M.H.; et al. Characterization of a novel coronavirus associated with severe acute respiratory syndrome. Science 2003, 300, 1394-1399. [CrossRef]

3. Zhu, N.; Zhang, D.; Wang, W.; Li, X.; Yang, B.; Song, J.; Zhao, X.; Huang, B.; Shi, W.; Lu, R.; et al. A novel coronavirus from patients with pneumonia in China, 2019. N. Engl. J. Med. 2020, 382, 727-733. [CrossRef] 
4. Kin, N.; Miszczak, F.; Lin, W.; Gouilh, M.A.; Vabret, A.; Epicorem Consortium. Genomic analysis of 15 human coronaviruses OC43 (HCoV-OC43s) circulating in France from 2001 to 2013 reveals a high intra-specific diversity with new recombinant genotypes. Viruses 2015, 7, 2358-2377. [CrossRef]

5. Casais, R.; Thiel, V.; Siddell, S.G.; Cavanagh, D.; Britton, P. Reverse genetics system for the avian coronavirus infectious bronchitis virus. J. Virol. 2001, 75, 12359-12369. [CrossRef]

6. Bande, F.; Arshad, S.S.; Omar, A.R.; Bejo, M.H.; Abubakar, M.S.; Abba, Y. Pathogenesis and diagnostic approaches of avian infectious bronchitis. Adv. Virol. 2016, 2016, 4621659. [CrossRef]

7. Okino, C.H.; Mores, M.A.; Trevisol, I.M.; Coldebella, A.; Montassier, H.J.; Brentano, L. Early immune responses and development of pathogenesis of avian infectious bronchitis viruses with different virulence profiles. PLOS ONE 2017, 12, e0172275. [CrossRef]

8. Ignjatovic, J.; Sapats, S. Avian infectious bronchitis virus. Rev. Sci. Tech. 2000, 19, 493-508. [CrossRef]

9. Wang, Y.; Wang, Y.; Zhang, Z.; Fan, G.; Jiang, Y.; Liu, X.; Ding, J.; Wang, S. Isolation and identification of glandular stomach type IBV (QX IBV) in chickens. Chin. J. Anim. Quar. 1998, 15, 1-3.

10. Jackwood, M.W. Review of infectious bronchitis virus around the world. Avian Dis. 2012, 56, 634-641. [CrossRef]

11. Boursnell, M.E.; Brown, T.D.; Foulds, I.J.; Green, P.F.; Tomley, F.M.; Binns, M.M. Completion of the sequence of the genome of the coronavirus avian infectious bronchitis virus. J. Gen. Virol. 1987, 68, 57-77. [CrossRef]

12. Boursnell, M.E.; Brown, T.D.; Foulds, I.J.; Green, P.F.; Tomley, F.M.; Binns, M.M. The complete nucleotide sequence of avian infectious bronchitis virus: Analysis of the polymerase-coding region. Adv. Exp. Med. Biol. 1987, 218, 15-29.

13. Brierley, I.; Boursnell, M.E.; Binns, M.M.; Bilimoria, B.; Blok, V.C.; Brown, T.D.; Inglis, S.C. An efficient ribosomal frame-shifting signal in the polymerase-encoding region of the coronavirus IBV. EMBO J. 1987, 6, 3779-3785. [CrossRef]

14. Brierley, I.; Digard, P.; Inglis, S.C. Characterization of an efficient coronavirus ribosomal frameshifting signal: Requirement for an RNA pseudoknot. Cell 1989, 57, 537-547. [CrossRef]

15. Lai, M.M.; Cavanagh, D. The molecular biology of coronaviruses. Adv. Virus Res. 1997, 48, 1-100.

16. Shang, J.; Zheng, Y.; Yang, Y.; Liu, C.; Geng, Q.; Luo, C.; Zhang, W.; Li, F. Cryo-EM structure of infectious bronchitis coronavirus spike protein reveals structural and functional evolution of coronavirus spike proteins. PLoS Pathog. 2018, 14, e1007009. [CrossRef]

17. Bickerton, E.; Maier, H.J.; Stevenson-Leggett, P.; Armesto, M.; Britton, P. The S2 subunit of infectious bronchitis virus beaudette is a determinant of cellular tropism. J. Virol. 2018, 92, e01044-18. [CrossRef]

18. Casais, R.; Dove, B.; Cavanagh, D.; Britton, P. Recombinant avian infectious bronchitis virus expressing a heterologous spike gene demonstrates that the spike protein is a determinant of cell tropism. J. Virol. 2003, 77, 9084-9089. [CrossRef]

19. Wickramasinghe, I.N.; de Vries, R.P.; Grone, A.; de Haan, C.A.; Verheije, M.H. Binding of avian coronavirus spike proteins to host factors reflects virus tropism and pathogenicity. J. Virol. 2011, 85, 8903-8912. [CrossRef]

20. Hodgson, T.; Casais, R.; Dove, B.; Britton, P.; Cavanagh, D. Recombinant infectious bronchitis coronavirus Beaudette with the spike protein gene of the pathogenic M41 strain remains attenuated but induces protective immunity. J. Virol. 2004, 78, 13804-13811. [CrossRef]

21. Winter, C.; Schwegmann-Wessels, C.; Cavanagh, D.; Neumann, U.; Herrler, G. Sialic acid is a receptor determinant for infection of cells by avian Infectious bronchitis virus. J. Gen. Virol. 2006, 87, 1209-1216. [CrossRef]

22. Abd El Rahman, S.; El-Kenawy, A.A.; Neumann, U.; Herrler, G.; Winter, C. Comparative analysis of the sialic acid binding activity and the tropism for the respiratory epithelium of four different strains of avian infectious bronchitis virus. Avian Pathol. 2009, 38, 41-45. [CrossRef]

23. Chhabra, R.; Ball, C.; Chantrey, J.; Ganapathy, K. Differential innate immune responses induced by classical and variant infectious bronchitis viruses in specific pathogen free chicks. Dev. Comp. Immunol. 2018, 87, 16-23. [CrossRef]

24. Chhabra, R.; Kuchipudi, S.V.; Chantrey, J.; Ganapathy, K. Pathogenicity and tissue tropism of infectious bronchitis virus is associated with elevated apoptosis and innate immune responses. Virology 2016, 488, 232-241. [CrossRef]

25. Cavanagh, D. Severe acute respiratory syndrome vaccine development: Experiences of vaccination against avian infectious bronchitis coronavirus. Avian Pathol. 2003, 32, 567-582. [CrossRef] 
26. De Wit, J.J. Detection of infectious bronchitis virus. Avian Pathol. 2000, 29, 71-93. [CrossRef]

27. Jordan, B. Vaccination against infectious bronchitis virus: A continuous challenge. Vet. Microbiol. 2017, 206, 137-143. [CrossRef]

28. De Wit, J.J.; Cook, J.K.; Van der Heijden, H.M. Infectious bronchitis virus variants: A review of the history, current situation and control measures. Avian Pathol. 2011, 40, 223-235. [CrossRef]

29. Shimazaki, Y.; Watanabe, Y.; Harada, M.; Seki, Y.; Kuroda, Y.; Fukuda, M.; Honda, E.; Suzuki, S.; Nakamura, S. Genetic analysis of the S1 gene of $4 / 91$ type infectious bronchitis virus isolated in Japan. J. Vet. Med. Sci. 2009, 71, 583-588. [CrossRef]

30. Xu, C.; Zhao, J.; Hu, X.; Zhang, G. Isolation and identification of four infectious bronchitis virus strains in China and analyses of their S1 glycoprotein gene. Vet. Microbiol. 2007, 122, 61-71. [CrossRef]

31. Kameka, A.M.; Haddadi, S.; Kim, D.S.; Cork, S.C.; Abdul-Careem, M.F. Induction of innate immune response following infectious bronchitis corona virus infection in the respiratory tract of chickens. Virology 2014, 450, 114-121. [CrossRef]

32. Bailey, C.C.; Zhong, G.; Huang, I.C.; Farzan, M. IFITM-family proteins: The cell's first line of antiviral defense. Annu. Rev. Virol. 2014, 1, 261-283. [CrossRef]

33. Munoz-Moreno, R.; Cuesta-Geijo, M.A.; Martinez-Romero, C.; Barrado-Gil, L.; Galindo, I.; Garcia-Sastre, A.; Alonso, C. Antiviral Role of IFITM Proteins in African Swine Fever Virus Infection. PLoS ONE 2016, 11, e0154366. [CrossRef]

34. Blyth, G.A.; Chan, W.F.; Webster, R.G.; Magor, K.E. Duck interferon-inducible transmembrane protein 3 mediates restriction of influenza viruses. J. Virol. 2016, 90, 103-116. [CrossRef]

35. Chen, S.; Luo, G.; Yang, Z.; Lin, S.; Chen, S.; Wang, S.; Goraya, M.U.; Chi, X.; Zeng, X.; Chen, J.L. Avian Tembusu virus infection effectively triggers host innate immune response through MDA5 and TLR3-dependent signaling pathways. Vet. Res. 2016, 47, 74. [CrossRef]

36. Diamond, M.S.; Farzan, M. The broad-spectrum antiviral functions of IFIT and IFITM proteins. Nat. Rev. Immunol. 2013, 13, 46-57. [CrossRef]

37. Brass, A.L.; Huang, I.C.; Benita, Y.; John, S.P.; Krishnan, M.N.; Feeley, E.M.; Ryan, B.J.; Weyer, J.L.; van der Weyden, L.; Fikrig, E.; et al. The IFITM proteins mediate cellular resistance to influenza A H1N1 virus, West Nile virus, and dengue virus. Cell 2009, 139, 1243-1254. [CrossRef]

38. Huang, I.C.; Bailey, C.C.; Weyer, J.L.; Radoshitzky, S.R.; Becker, M.M.; Chiang, J.J.; Brass, A.L.; Ahmed, A.A.; Chi, X.; Dong, L.; et al. Distinct patterns of IFITM-mediated restriction of filoviruses, SARS coronavirus, and influenza A virus. PLoS Pathog. 2011, 7, e1001258. [CrossRef]

39. Lu, J.; Pan, Q.; Rong, L.; He, W.; Liu, S.L.; Liang, C. The IFITM proteins inhibit HIV-1 infection. J. Virol. 2011, 85, 2126-2137. [CrossRef]

40. Perreira, J.M.; Chin, C.R.; Feeley, E.M.; Brass, A.L. IFITMs restrict the replication of multiple pathogenic viruses. J. Mol. Biol. 2013, 425, 4937-4955. [CrossRef]

41. Smith, J.; Smith, N.; Yu, L.; Paton, I.R.; Gutowska, M.W.; Forrest, H.L.; Danner, A.F.; Seiler, J.P.; Digard, P.; Webster, R.G.; et al. A comparative analysis of host responses to avian influenza infection in ducks and chickens highlights a role for the interferon-induced transmembrane proteins in viral resistance. BMC Genom. 2015, 16, 574. [CrossRef]

42. Smith, S.; Weston, S.; Kellam, P.; Marsh, M. IFITM proteins-cellular inhibitors of viral entry. Curr. Opin. Virol. 2014, 4, 71-77. [CrossRef]

43. Wilkins, C.; Woodward, J.; Lau, D.T.; Barnes, A.; Joyce, M.; McFarlane, N.; McKeating, J.A.; Tyrrell, D.L.; Gale, M., Jr. IFITM1 is a tight junction protein that inhibits hepatitis C virus entry. Hepatology 2013, 57, 461-469. [CrossRef]

44. Wilkins, J.; Zheng, Y.M.; Yu, J.; Liang, C.; Liu, S.L. Nonhuman Primate IFITM Proteins Are Potent Inhibitors of HIV and SIV. PLoS ONE 2016, 11, e0156739. [CrossRef]

45. Desai, T.M.; Marin, M.; Chin, C.R.; Savidis, G.; Brass, A.L.; Melikyan, G.B. IFITM3 restricts influenza A virus entry by blocking the formation of fusion pores following virus-endosome hemifusion. PLoS Pathog. 2014, 10, e1004048. [CrossRef]

46. Li, K.; Markosyan, R.M.; Zheng, Y.M.; Golfetto, O.; Bungart, B.; Li, M.; Ding, S.; He, Y.; Liang, C.; Lee, J.C. IFITM proteins restrict viral membrane hemifusion. PLoS Pathog. 2013, 9, e1003124. [CrossRef]

47. Weston, S.; Czieso, S.; White, I.J.; Smith, S.E.; Wash, R.S.; Diaz-Soria, C.; Kellam, P.; Marsh, M. Alphavirus Restriction by IFITM Proteins. Traffic 2016, 17, 997-1013. [CrossRef] 
48. Zhao, X.; Li, J.; Winkler, C.A.; An, P.; Guo, J.T. IFITM Genes, Variants, and Their Roles in the Control and Pathogenesis of Viral Infections. Front. Microbiol. 2018, 9, 3228. [CrossRef]

49. Amini-Bavil-Olyaee, S.; Choi, Y.J.; Lee, J.H.; Shi, M.; Huang, I.C.; Farzan, M.; Jung, J.U. The antiviral effector IFITM3 disrupts intracellular cholesterol homeostasis to block viral entry. Cell Host Microbe 2013, 13, $452-464$. [CrossRef]

50. Smith, S.E.; Gibson, M.S.; Wash, R.S.; Ferrara, F.; Wright, E.; Temperton, N.; Kellam, P.; Fife, M. Chicken interferon-inducible transmembrane protein 3 restricts influenza viruses and lyssaviruses in vitro. J. Virol. 2013, 87, 12957-12966. [CrossRef]

51. Bassano, I.; Ong, S.H.; Lawless, N.; Whitehead, T.; Fife, M.; Kellam, P. Accurate characterization of the IFITM locus using MiSeq and PacBio sequencing shows genetic variation in Galliformes. BMC Genom. 2017, 18, 419. [CrossRef]

52. Yu, J.; Li, M.; Wilkins, J.; Ding, S.; Swartz, T.H.; Esposito, A.M.; Zheng, Y.M.; Freed, E.O.; Liang, C.; Chen, B.K. IFITM Proteins Restrict HIV-1 Infection by Antagonizing the Envelope Glycoprotein. Cell Rep. 2015, 13, 145-156. [CrossRef]

53. Yu, Y.Y.; Shi, G.C. The antivirual function of ifitm 3 in influenza A virus infection. Chin. J. Tuberc. Respir. Dis. 2017, 40, 294-297.

54. Ellis, S.; Keep, S.; Britton, P.; de Wit, S.; Bickerton, E.; Vervelde, L. Recombinant infectious bronchitis viruses expressing chimeric spike glycoproteins induce partial protective immunity against homologous challenge despite limited replication in vivo. J. Virol. 2018, 92, e01473-18. [CrossRef]

55. Keep, S.; Stevenson-Leggett, P.; Steyn, A.; Oade, M.S.; Webb, I.; Stuart, J.; Vervelde, L.; Britton, P.; Maier, H.J.; Bickerton, E. Temperature sensitivity: A potential method for the generation of vaccines against the avian coronavirus infectious bronchitis virus. Viruses 2020, 12, 754. [CrossRef]

56. Van Roekel, H.C.M.; Bullis, K.L.; Olesiuk, O.M.; Sperling, F.G. Infectious bronchitis. Am. J. Vet. Res. 1951, 12, 140-146.

57. De Wit, J.J.; Nieuwenhuisen-van Wilgen, J.; Hoogkamer, A.; van de Sande, H.; Zuidam, G.J.; Fabri, T.H. Induction of cystic oviducts and protection against early challenge with infectious bronchitis virus serotype D388 (genotype QX) by maternally derived antibodies and by early vaccination. Avian Pathol. 2011, 40, 463-471. [CrossRef]

58. Keep, S.; Bickerton, E.; Armesto, M.; Britton, P. The ADRP domain from a virulent strain of infectious bronchitis virus is not sufficient to confer a pathogenic phenotype to the attenuated Beaudette strain. J. Gen. Virol. 2018, 99, 1097-1102. [CrossRef]

59. Bickerton, E.; Dowgier, G.; Britton, P. Recombinant infectious bronchitis viruses expressing heterologous S1 subunits: Potential for a new generation of vaccines that replicate in Vero cells. J. Gen. Virol. 2018, 99, 1681-1685. [CrossRef]

60. Penzes, Z.; Tibbles, K.; Shaw, K.; Britton, P.; Brown, T.D.; Cavanagh, D. Characterization of a replicating and packaged defective RNA of avian coronavirus infectious bronchitis virus. Virology 1994, 203, 286-293. [CrossRef]

61. Penzes, Z.; Wroe, C.; Brown, T.D.; Britton, P.; Cavanagh, D. Replication and packaging of coronavirus infectious bronchitis virus defective RNAs lacking a long open reading frame. J. Virol. 1996, 70, 8660-8668. [CrossRef] [PubMed]

62. Stirrups, K.; Shaw, K.; Evans, S.; Dalton, K.; Cavanagh, D.; Britton, P. Leader switching occurs during the rescue of defective RNAs by heterologous strains of the coronavirus infectious bronchitis virus. J. Gen. Virol. 2000, 81, 791-801. [CrossRef] [PubMed]

63. Hennion, R.M.; Hill, G. The preparation of chicken kidney cell cultures for virus propagation. Methods Mol. Biol. 2015, 1282, 57-62. [PubMed]

64. Hennion, R.M. The preparation of chicken tracheal organ cultures for virus isolation, propagation, and titration. Methods Mol. Biol. 2015, 1282, 51-56. [PubMed]

65. Cook, J.K.; Orbell, S.J.; Woods, M.A.; Huggins, M.B. Breadth of protection of the respiratory tract provided by different live-attenuated infectious bronchitis vaccines against challenge with infectious bronchitis viruses of heterologous serotypes. Avian Pathol. 1999, 28, 477-485. [CrossRef] [PubMed]

66. Keep, S.M.; Bickerton, E.; Britton, P. Transient dominant selection for the modification and generation of recombinant infectious bronchitis coronaviruses. Methods Mol. Biol. 2015, 1282, 115-133.

67. Reemers, S.S.; Groot Koerkamp, M.J.; Holstege, F.C.; van Eden, W.; Vervelde, L. Cellular host transcriptional responses to influenza A virus in chicken tracheal organ cultures differ from responses in in vivo infected trachea. Vet. Immunol. Immunopathol. 2009, 132, 91-100. [CrossRef] 
68. Armesto, M.; Cavanagh, D.; Britton, P. The replicase gene of avian coronavirus infectious bronchitis virus is a determinant of pathogenicity. PLoS ONE 2009, 4, e7384. [CrossRef]

69. Maier, H.J.; Hawes, P.C.; Cottam, E.M.; Mantell, J.; Verkade, P.; Monaghan, P.; Wileman, T.; Britton, P. Infectious bronchitis virus generates spherules from zippered endoplasmic reticulum membranes. MBio 2013, 4, e00801-e00813. [CrossRef]

70. Staines, K.; Batra, A.; Mwangi, W.; Maier, H.J.; Van Borm, S.; Young, J.R.; Fife, M.; Butter, C. A versatile panel of reference gene assays for the measurement of chicken mRNA by quantitative PCR. PLoS ONE 2016, 11, e0160173. [CrossRef]

71. Reddy, V.R.; Trus, I.; Desmarets, L.M.; Li, Y.; Theuns, S.; Nauwynck, H.J. Productive replication of nephropathogenic infectious bronchitis virus in peripheral blood monocytic cells, a strategy for viral dissemination and kidney infection in chickens. Vet. Res. 2016, 47, 70. [CrossRef] [PubMed]

72. Bailey, C.C.; Huang, I.C.; Kam, C.; Farzan, M. Ifitm3 limits the severity of acute influenza in mice. PLoS Pathog. 2012, 8, e1002909. [CrossRef] [PubMed]

73. Everitt, A.R.; Clare, S.; Pertel, T.; John, S.P.; Wash, R.S.; Smith, S.E.; Chin, C.R.; Feeley, E.M.; Sims, J.S.; Adams, D.J.; et al. IFITM3 restricts the morbidity and mortality associated with influenza. Nature 2012, 484, 519-523. [CrossRef] [PubMed]

74. Everitt, A.R.; Clare, S.; McDonald, J.U.; Kane, L.; Harcourt, K.; Ahras, M.; Lall, A.; Hale, C.; Rodgers, A.; Young, D.B.; et al. Defining the range of pathogens susceptible to Ifitm3 restriction using a knockout mouse model. PLoS ONE 2013, 8, e80723. [CrossRef]

75. Wrensch, F.; Winkler, M.; Pohlmann, S. IFITM proteins inhibit entry driven by the MERS-coronavirus spike protein: Evidence for cholesterol-independent mechanisms. Viruses 2014, 6, 3683-3698. [CrossRef]

76. Zhao, X.; Guo, F.; Liu, F.; Cuconati, A.; Chang, J.; Block, T.M.; Guo, J.T. Interferon induction of IFITM proteins promotes infection by human coronavirus OC43. Proc. Natl. Acad. Sci. USA 2014, 111, 6756-6761. [CrossRef]

77. Chen, B.Y.; Hosi, S.; Nunoya, T.; Itakura, C. Histopathology and immunohistochemistry of renal lesions due to infectious bronchitis virus in chicks. Avian Pathol. 1996, 25, 269-283. [CrossRef]

78. Owen, R.L.; Cowen, B.S.; Hattel, A.L.; Naqi, S.A.; Wilson, R.A. Detection of viral antigen following exposure of one-day-old chickens to the Holland 52 strain of infectious bronchitis virus. Avian Pathol. 1991, 20, 663-673. [CrossRef]

79. Cong, F.; Liu, X.; Han, Z.; Shao, Y.; Kong, X.; Liu, S. Transcriptome analysis of chicken kidney tissues following coronavirus avian infectious bronchitis virus infection. BMC Genom. 2013, 14, 743. [CrossRef]

80. Wang, H.N.; Wu, Q.Z.; Huang, Y.; Liu, P. Isolation and identification of infectious bronchitis virus from chickens in Sichuan, China. Avian Dis. 1997, 41, 279-282. [CrossRef]

81. Winter, C.; Herrler, G.; Neumann, U. Infection of the tracheal epithelium by infectious bronchitis virus is sialic acid dependent. Microbes Infect. 2008, 10, 367-373. [CrossRef] [PubMed]

82. Kint, J.; Fernandez-Gutierrez, M.; Maier, H.J.; Britton, P.; Langereis, M.A.; Koumans, J.; Wiegertjes, G.F.; Forlenza, M. Activation of the chicken type I interferon response by infectious bronchitis coronavirus. J. Virol. 2015, 89, 1156-1167. [CrossRef] [PubMed]

83. Kint, J.; Dickhout, A.; Kutter, J.; Maier, H.J.; Britton, P.; Koumans, J.; Pijlman, G.P.; Fros, J.J.; Wiegertjes, G.F.; Forlenza, M. Infectious bronchitis coronavirus inhibits STAT1 signaling and requires accessory proteins for resistance to type I interferon activity. J. Virol. 2015, 89, 12047-12057. [CrossRef] [PubMed]

84. Kint, J.; Langereis, M.A.; Maier, H.J.; Britton, P.; van Kuppeveld, F.J.; Koumans, J.; Wiegertjes, G.F.; Forlenza, M. Infectious bronchitis coronavirus limits interferon production by inducing a host shutoff that requires accessory protein 5b. J. Virol. 2016, 90, 7519-7528. [CrossRef] [PubMed]

85. Laconi, A.; van Beurden, S.J.; Berends, A.J.; Kramer-Kuhl, A.; Jansen, C.A.; Spekreijse, D.; Chenard, G.; Philipp, H.C.; Mundt, E.; Rottier, P.J.M.; et al. Deletion of accessory genes 3a, 3b, 5a or 5b from avian coronavirus infectious bronchitis virus induces an attenuated phenotype both in vitro and in vivo. J. Gen. Virol. 2018, 99, 1381. [CrossRef] [PubMed]

(C) 2020 by the authors. Licensee MDPI, Basel, Switzerland. This article is an open access article distributed under the terms and conditions of the Creative Commons Attribution (CC BY) license (http://creativecommons.org/licenses/by/4.0/). 